\title{
Effect of inhibition of the adrenomedullin gene on the growth and chemosensitivity of ovarian cancer cells
}

\author{
PAN CHEN $^{1,2^{*}}$, XIAOYAN PANG ${ }^{*}$, YI ZHANG $^{1}$ and YUNQIN HE ${ }^{2}$ \\ ${ }^{1}$ Department of Gynecology, The First Affiliated Hospital of China Medical University, Shenyang 110001, Liaoning; \\ ${ }^{2}$ Department of Gynecology and Obstetrics, Jinhua Municipal Central Hospital, Jinhua 321000, Zhejiang, P.R. China
}

Received November 20, 2011; Accepted December 22, 2011

DOI: 10.3892/or.2012.1655

\begin{abstract}
Adrenomedullin (AM), a potent vasodilator peptide, is present in various types of tumors. Here, we constructed short hairpin RNA (shRNA) in order to target the AM gene in vitro using RNA interference (RNAi) technology. HO8910 ovarian cancer cells were transfected, and the effects of AM on proliferation and chemosensitivity of the cells were examined. RT-PCR, real-time PCR and western blot analysis were performed to detect the AM gene and protein expression. The MTT assay was used to observe the effect of AM on proliferation and chemosensitivity of the cells. Also, the protein levels of Bcl-2 and the extracellular regulated protein kinase (ERK) were evaluated by western blot analysis. We found that silencing of the AM gene inhibited the proliferation and increased the chemosensitivity of HO8910 cells, reduced the expression of AM mRNA and protein as well as downregulated Bcl-2 and p-ERK expression. We, therefore, conclude that silencing of the AM gene in HO8910 ovarian cancer cells inhibited the proliferation and increased the chemosensitivity of the cells through downregulation of ERK and Bcl-2 expression. Thus, anti-AM treatment together with suppression of ERK and Bcl-2 expression provides a novel research approach for ovarian cancer.
\end{abstract}

\section{Introduction}

Ovarian cancer is one of the most common causes of death from all cancers among women and the leading cause of death from gynecological malignancies. Despite the initial surgery and chemotherapy to achieve complete remission, most patients will still relapse within two or three years. In addition, chemotherapy resistance frequently develops, mostly in patients

Correspondence to: Dr Yi Zhang, Department of Gynecology, The First Affiliated Hospital of China Medical University, 155 Nanjing North Street, Shenyang 110001, Liaoning, P.R. China

E-mail: syzi960@yahoo.com

${ }^{*}$ Contributed equally

Key words: ovarian cancer, adrenomedullin gene, RNA interference, chemosensitivity with poor prognosis. Conventional surgery and chemotherapy cannot significantly improve the survival rate of patients with advanced cancer. Targeted gene therapy is currently a growing consideration, and has become a new trend in the treatment of various types of cancer. Therefore, it is of interest to find effective therapeutic targets for intervention strategies that target the tumors and at the same time offset the side effects caused by chemotherapy.

Adrenomedullin (AM) is a potent vasodilator peptide widely distributed in various tumor tissues. Induced by hypoxia, AM involves in tumor angiogenesis, inhibiting apoptosis, immune escape and other processes which seem to have an important role in tumor growth, invasion, metastasis and other biological behaviors $(1,2)$. Recent studies have indicated that AM highly expressed in ovarian cancer and its expression level was an important indicator of invasive ovarian cancer (1). In our previous studies, we found that AM significantly promoted the proliferation of ovarian cancer CAOV3 cells (3), while the AM receptor antagonist (AM22-52) had opposite effects (4).

In the present study, we constructed short hairpin RNA (shRNA) targeting the AM gene in vitro with RNA interference (RNAi) technology, transfected ovarian cancer HO8910 cells, and observed the effect of AM on proliferation and chemosensitivity of the cells.

\section{Materials and methods}

Reagents. RPMI-1640 medium was purchased from the Hyclone Co. (Logan, UT). TRIzol, Lipofectamine 2000 and vector pRNAU-6.1/neo were from Invitrogen (Carlsbad, CA). The RT-PCR kit and DNA markers were from Takara (Dalian, China). Agarose gel was from Promega (Madison, WI). Rabbitanti-human-AM and rabbit-anti-human-Bcl-2 polyclonal antibodies were from Phoenix Pharmaceuticals (Belmont, CA). Rabbit-anti-human-ERK (extracellular signal-regulated kinase) and rabbit-anti-human-p-ERK polyclonal antibodies were from Boster Wuhai Biological Technology Ltd. (Wuhan, China). Peroxidase-conjugated goat anti-rabbit antibody and $\beta$-naphthyl acid phosphate were from Sigma (St. Louis, MO). All other chemicals used were of analytical reagent grade.

Construction of expression vector. According to shRNA design principles, AM coding sequences (GenBank Accession 
Table I. Short hairpin RNA sequences designed with the GenScript siRNA target finder.

Gene Sequence

Oligo 263 F: 5'-GATCCCGCGTCGGAGTTTCGAAAGAAGTCTCGAGACTTCTTTCGAAACTCCGACGTTTTTTCCAAA-3' R: 5'-AGCTTTTGGAAAAAACGTCGGAGTTTCGAAAGAAGTCTCGAGACTTCTTTCGAAACTCCGACGCGG-3'

Oligo 643 F: 5'-GATCCCGCTGGTGTCTTCTAAGCCACAACTCGAGTTGTGGCTTAGAAGACACCAGTTTTTTCCAAA-3' R: 5'-AGCTTTTGGAAAAAACTGGTGTCTTCTAAGCCACAACTCGAGTTGTGGCTTAGAAGACACCAGCGG-3'

Oligo 1143 F: 5'-GATCCCGTACATACAGAGGTAACTATCCTCGAGGATAGTTACCTCTGTATGTACTTTTTTCCAAA-3' R: 5'-AGCTTTTGGAAAAAAGTACATACAGAGGTAACTATCCTCGAGGATAGTTACCTCTGTATGTACGG-3'

Oligo 2 F: 5'-GATCCCGTTCTCCGAACGTGTCACGTTTGATATCCGACGTGACACGTTCGGAGAATTTTTTCCAAA-3' R: 5'-AGCTTTTGGAAAAAATTCTCCGAACGTGTCACGTCGGATATCAAACGTGACACGTTCGGAGAACGG-3'

Oligo 263, Oligo 643, Oligo 1143, three different RNAi sequences targeting AM; Oligo 2, negative control shRNA (no silence sequence).

no. NM_001124.1) were searched in GenBank. Then, shRNA sequences targeted AM were designed with Genscript siRNA target finder (Table I). The shRNA sequences were submitted to BLAST http://www.ncbi.nlm.nih.gov/blast/ to ensure their specificity of targeting. Finally, pRNAU-6.1/neo was selected as the RNAi expression vector. The double-stranded short hairpin DNA was annealed, ligated into the restriction sites between BamHI and XhoI in pRNAU-6.1/neo with T4 DNA ligase, and then transfected into $E$. coli DH5 $\alpha$. Resistance screening, agarose gel electrophoresis and DNA sequencing were used to check the recombinant plasmid, named pRNAU6.1/neo-AM shRNA or AM shRNA.

Cell culture and grouping. The human ovarian cancer HO8910 cells were provided by the Department of Cell Biology of the China Medical University and cultured in RPMI-1640 containing 10\% fetal bovine serum and penicillin/ streptomycin $(100 \mathrm{U} / \mathrm{ml})$. Cell cultures were maintained in a humidified atmosphere containing $5 \% \mathrm{CO}_{2}$ at $37^{\circ} \mathrm{C}$, and the growth medium was renewed every 2-3 days. Cells were divided in three groups: the HO8910 group (untransfected), the no silence shRNA group (transfected with no silence shRNA or nos shRNA), and the AM shRNA group (transfected with AM shRNA, named AM shRNA1, AM shRNA2, and AM shRNA3, respectively).

Cell transfection. HO8910 cells $\left(5 \times 10^{4}\right)$ were plated in 6-well plates and allowed to adhere for $24 \mathrm{~h}$. Plasmid DNA was transfected into HO8910 cells using Lipofectamine ${ }^{\mathrm{TM}} 2000$. Briefly, cells were transfected using $2 \mu \mathrm{g}$ DNA mixed with $5 \mu \mathrm{l}$ Lipofectamine in $1 \mathrm{ml}$ medium without serum or antibiotics. The cells were incubated for $24 \mathrm{~h}$, and then $1 \mathrm{ml}$ medium containing $20 \%$ serum was added to each well. The cells were cultured and screened in medium containing $10 \%$ serum and $400 \mu \mathrm{g} / \mathrm{ml} \mathrm{G} 418$ for at least 3 weeks. Then, stable transfectants were formed.

$R T$-PCR. Total RNA was extracted from HO8910 cells using TRIzol Reagent following the manufacture's instructions. Purity and quantity of the RNA was assessed by spectrophotometry (A260/280 greater than 1.8). cDNA was synthesized from $2 \mu \mathrm{g}$ of total RNA using an RT-PCR kit. Primer sequences used for AM detection were as follows, sense 5'-TCCCCCTA TTTTAAGACGTGAATG-3', antisense 5'-CATGCACACA AACACACTCACAT-3'. The housekeeping gene glyceraldehyde phosphate dehydrogenase (GAPDH) was used for normalization (sense 5'-ATCTGGCACCACACCTTC-3', antisense 5'-AGCCAGGTCCAGACGCA-3'). The amplification conditions consisted of an initial denaturation step at $94^{\circ} \mathrm{C}$ for $2 \mathrm{~min}$, then 27 cycles of $94^{\circ} \mathrm{C}$ for $1 \mathrm{~min}, 60^{\circ} \mathrm{C}$ for $1 \mathrm{~min}$, and followed by extension at $72^{\circ} \mathrm{C}$ for $1 \mathrm{~min}$. PCR products were analyzed by $1.2 \%$ agarose gel electrophoresis with ethidium bromide for UV light transilluminator visualization. The results were calculated as the ratio of the band optical density (OD) value to that of the GAPDH gene. Each experiment was repeated independently three times and the mean was obtained.

Real-time PCR. Total RNA was isolated with TRIzol Reagent from cells cultured in the absence or presence of AM shRNA for $24 \mathrm{~h}$. Real-time RT-PCR amplifications were carried out using DNase I (Promega)-treated total RNA. Reactions were performed in a Stratagene MX3000P system using the Realtime PCR Master Mix using GAPDH for normalization. The forward and reverse PCR primers were: AM, 5'-TCCCCCTA TTTTAAGACGTGAATG-3' and 5'-CATGCACACAAACA CACTCACAT-3'; GAPDH, 5'-GAAGGTGAAGGTCGGA GT-3' and 5'-GAAAGATGGTGATGGGATTTC-3'. The reaction conditions were $50^{\circ} \mathrm{C}$ for $2 \mathrm{~min}, 95^{\circ} \mathrm{C}$ for $10 \mathrm{~min}, 95^{\circ} \mathrm{C}$ for $30 \mathrm{sec}$ and $60^{\circ} \mathrm{C}$ for $30 \mathrm{sec}$ for 50 cycles. The $\Delta \mathrm{Ct}$ method was used to obtain relative expression values of AM mRNA as compared with GAPDH gene amplification. PCR reactions were performed in duplicate and each experiment was repeated 3-5 times.

Western blot analysis. Confluent cells were lysed in lysis buffer (0.01 mmol/1 Tris-HCl, $\mathrm{pH} 7.6,0.1 \mathrm{mmol} / \mathrm{l} \mathrm{NaCl}, 0.001 \mathrm{~mol} / \mathrm{l}$ EDTA, pH 8.0, $1 \mu \mathrm{g} / \mathrm{ml}$ Aprotinin, $100 \mu \mathrm{g} / \mathrm{ml} \mathrm{PMSF).} \mathrm{The} \mathrm{cell}$ lysate was incubated on ice for $15 \mathrm{~min}$ and then centrifuged at $17,000 \mathrm{x}$ g for $1 \mathrm{~h}$ at $4^{\circ} \mathrm{C}$. Protein concentration was determined using the Lowry method. Protein aliquots $(50 \mu \mathrm{g})$ were separated on $15 \%$ SDS-polyacrylamide gels and transferred to nitrocellulose filters. Non-specific binding sites were blocked by incubating the nitrocellulose membrane for $1 \mathrm{~h}$ at $37^{\circ} \mathrm{C}$ with $5 \%$ non-fat dried milk in Tris-buffered saline containing 


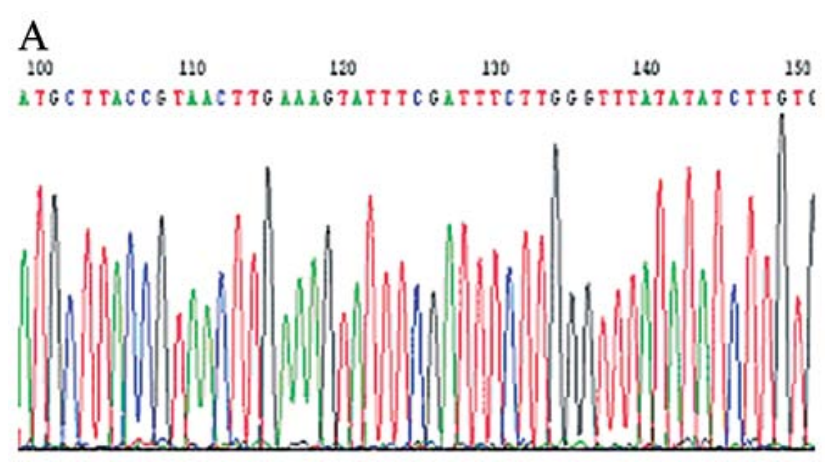

$\mathrm{C}_{\mathrm{man}}$ ।


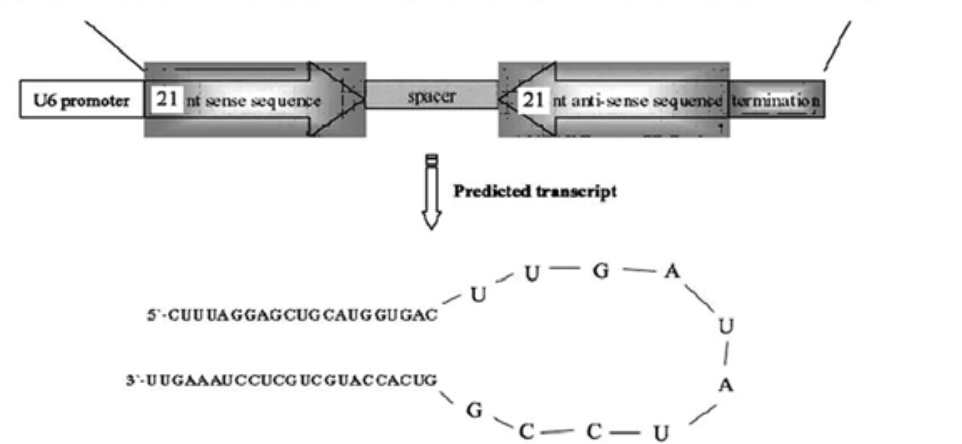

B
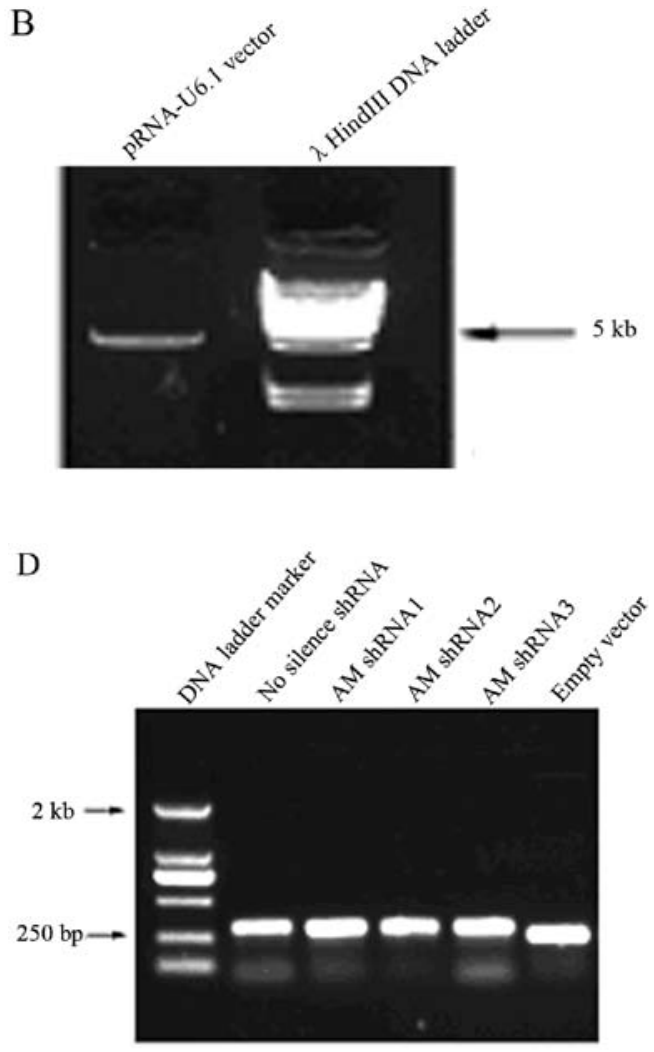

Figure 1. (A) Recombinant plasmid pRNAU-6.1/neo-AM shRNA sequence map (in part). (B) Expression vector pRNAU-6.1/neo was identified by restriction enzyme digestion. (C) Plasmid with RNA polymerase III promotor U6. (D) Three different RNAi sequences, no silence sequence, and empty plasmid were confirmed by PCR.

0.05\% Tween-20 (TBST). Membranes were incubated overnight at $4^{\circ} \mathrm{C}$ with primary antibodies (anti-AM, anti-ERK, anti-p-ERK, or anti-Bcl-2 antibody), then washed and incubated with a horseradish peroxidase conjugated secondary antibody. Bands were visualized using the enhanced chemiluminescence system (ECL). Each experiment was repeated three times and the mean was obtained.

Cell proliferation assay. Cell proliferation was determined by the 3-(4,5-dimethylthiazol-2-yl)-2,5-diphenyltetrazolium bromide (MTT) assay. Briefly, cells cultured in the absence or presence of AM shRNA or no silence shRNA for $24 \mathrm{~h}$ were seeded into a 96-well plate at a density of $5 \times 10^{5}$ cells/well. After being starved overnight in quiescent medium, the cells were cultured for $72 \mathrm{~h}$ with $10 \%$ FBS. Then, $20 \mu \mathrm{l}$ of MTT was added to each well and incubated for $4 \mathrm{~h}$ at $37^{\circ} \mathrm{C}$, which was followed by adding $150 \mu \mathrm{l} \mathrm{DMSO}$ and incubating at $37^{\circ} \mathrm{C}$ for an additional $10 \mathrm{~min}$. Absorbance was read at $570 \mathrm{~nm}$ on a microplate reader. Chemosensitivity analysis of carboplatin was as follows. Cells cultured in the absence or presence of AM shRNA or no silence shRNA for $24 \mathrm{~h}$ were seeded into a 96 -well plate at a density of $5 \times 10^{5}$ cells/well. After being anchored to the surface for $24 \mathrm{~h}$, cells were incubated with $10^{-4} \mathrm{~L}$ carboplatin, at a concentration ranging from $0-75 \mathrm{mg} / 1$ for $48 \mathrm{~h}$. Absorbance was read at $570 \mathrm{~nm}$ on a microplate reader.

Statistical analysis. The software package SPSS13.0 was used to analyze data. All values were presented as mean \pm standard deviation (SD). Means of every two different groups were

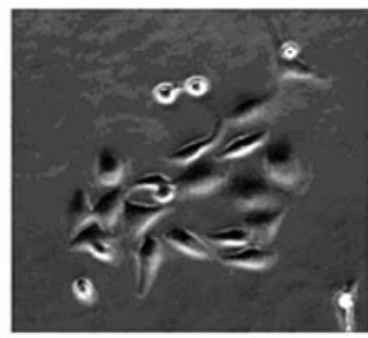

No silence shRNA cell

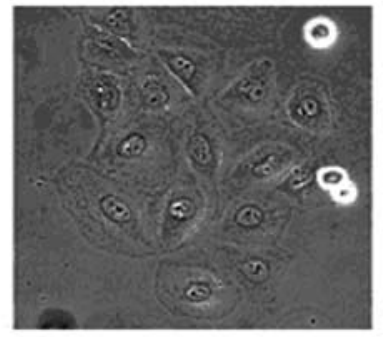

AM shRNA cell clone
Figure 2. Positive cell clones selected by G418 (original magnification, x400).

detected with the Student's t-test. A P-value $<0.05$ was defined as statistically significant.

\section{Results}

pRNAU-6.1/neo-AM shRNA sequencing results. DNA was sequenced from recombinant plasmids of positive single clone cells. The results showed that insert sequences were exactly the same as designed sequences, indicating that the AM expression vector was successfully constructed (Fig. 1).

Resistance cell clones after G418 selection. Recombinant plasmid pRNAU-6.1/neo-AM shRNA (AM shRNA) was transfected into HO8910 cells with G418 $(400 \mu \mathrm{g} / \mathrm{ml})$ for 7 days. G418 resistance cell clones (no silence shRNA and AM shRNA cells) were respectively obtained. Positive cell clones 

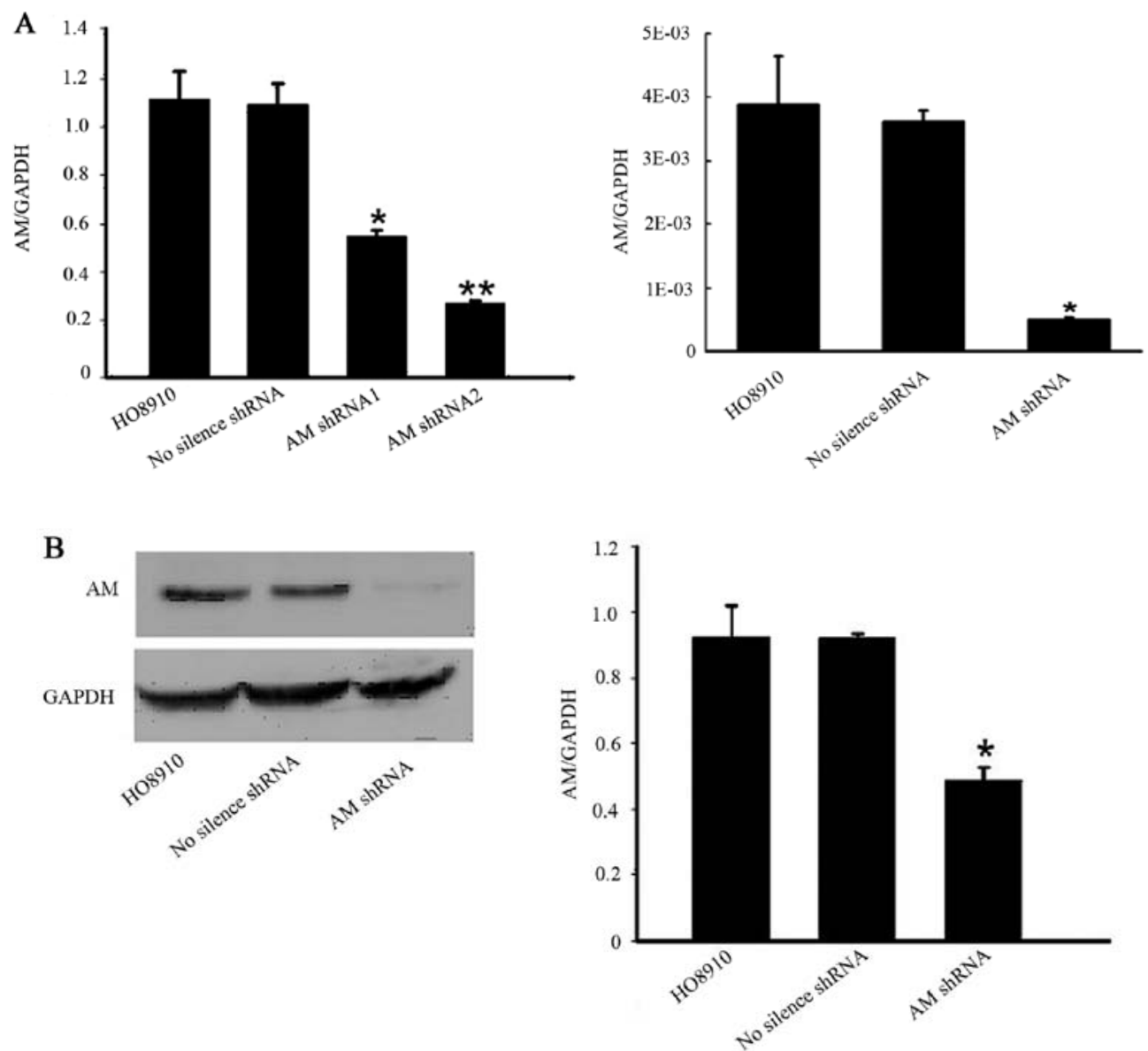

Figure 3. Effects of AM shRNA on HO8910 cells. (A) RT-PCR and real-time PCR were performed to detect the AM mRNA levels in the AM shRNA group, the no silence shRNA group and the HO8910 group. AM mRNA levels in the AM shRNA group were significantly reduced compared to the other two groups. The bar graph shows the results of three independent experiments. (B) Western blot analysis was performed to investigate the AM protein levels in three groups. AM protein levels in the AM shRNA group was significantly lower compared to the other two groups. GAPDH was used as the internal loading control. Data are mean \pm SEM from 3 separate experiments. ${ }^{*} \mathrm{P}<0.05,{ }^{* *} \mathrm{P}<0.01$ vs. the no silence shRNA group.

are shown in Fig. 2. Due to contamination during passage, AM shRNA3 cells were unsuccessfully cloned.

Specific silencing of the AM gene in HO8910 cells with AM shRNA. Two different AM shRNA and the no silence shRNA were separately transfected into HO8910 cells. At $24 \mathrm{~h}$ after transfection, AM mRNA and protein levels were assessed by RT-PCR, real-time PCR and western blot analysis, respectively. Of the two different AM shRNA, AM shRNA2 was found to have the highest inhibitory rate, reaching $52.34 \%$ by PCR (data not shown). Thus, we used AM shRNA2 for subsequent experiments.

As shown in Fig. 3, AM shRNA significantly reduced the AM mRNA and protein levels. Furthermore, there were significant differences between the AM shRNA group and the no silence shRNA group or the HO8910 group $(\mathrm{P}<0.05)$.

Silencing of AM inhibited the proliferation and increased chemosensitivity of HO8910 cells. The effect of AM silencing on the proliferation of HO8910 ovarian cancer cells was measured by the MTT assay. As shown in Fig. 4A, cells in the AM shRNA group showed retarded growth starting from the second day. The growth inhibition rate was $40 \%$ on the third day. There was a significant difference compared with the no silence shRNA group and the HO8910 group $(\mathrm{P}<0.05)$. The difference between the no silence shRNA group and the HO8910 group was not significant $(\mathrm{P}>0.05)$. However, after different concentrations of carboplatin treatment $(0-75 \mathrm{mg} / \mathrm{l})$, the survival rate in three different groups decreased. The effects were more pronounced in the shRNA group. As shown in Fig. 4B, the difference was significant compared with the no silence shRNA group or the HO8910 group $(\mathrm{P}<0.05)$.

Silencing of AM downregulated Bcl-2 and p-ERK expression in HO8910 cells. To investigate the relationship between AM and ERK or AM and Bcl-2 expression, western blot analysis was used to monitor the expression of Bcl-2 and p-ERK in the AM shRNA group and the no silence shRNA group. As shown in Fig. 5, inhibition of AM expression reduced the level of Bcl-2 or p-ERK expression, and there was a significant difference between the two different groups $(\mathrm{P}<0.05)$.

\section{Discussion}

The present study demonstrated that silencing of AM in ovarian cancer HO8910 cells with RNAi technology inhibited the proliferation and increased the chemosensitivity of the cells. 

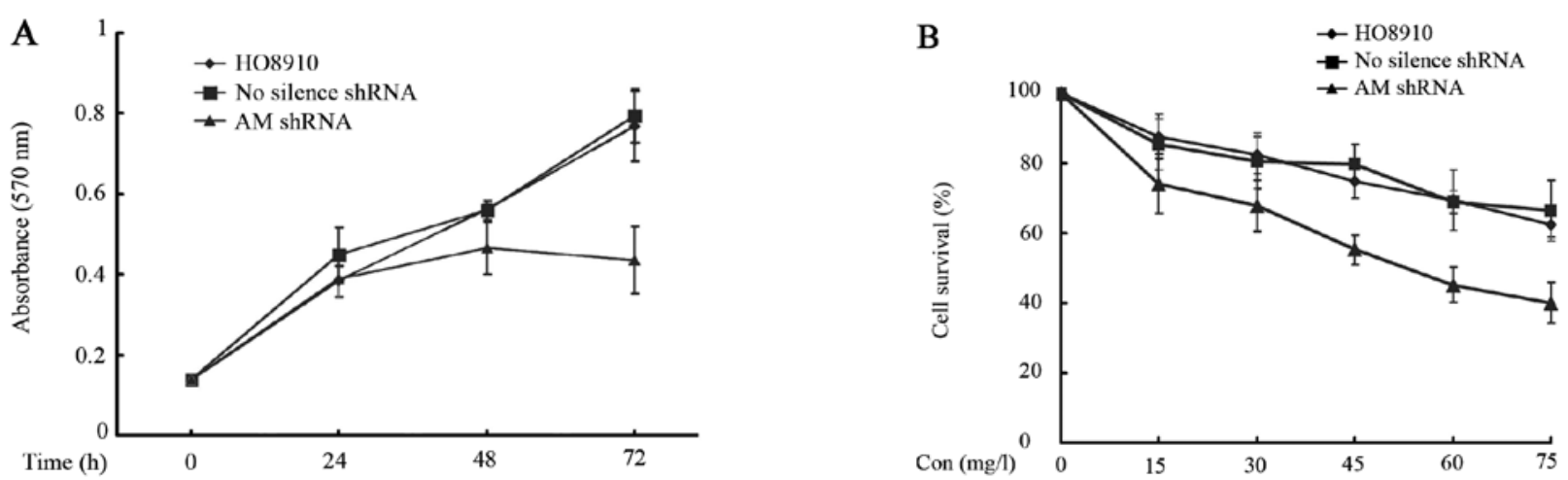

Figure 4. (A) The MTT assay was used to analyze of the proliferation of untransfected HO8910 cells and HO8910 cells $72 \mathrm{~h}$ after treatment with AM shRNA2 or no silence shRNA. The data presented are the absorbance \pm SD from three independent assays. (B) Chemosensitivity of cells in the normal control group, the negative control group or the specific transfection group investigated by the MTT assay. The data are expressed as percent cell survival \pm SD from three independent assays. Con, carboplatin
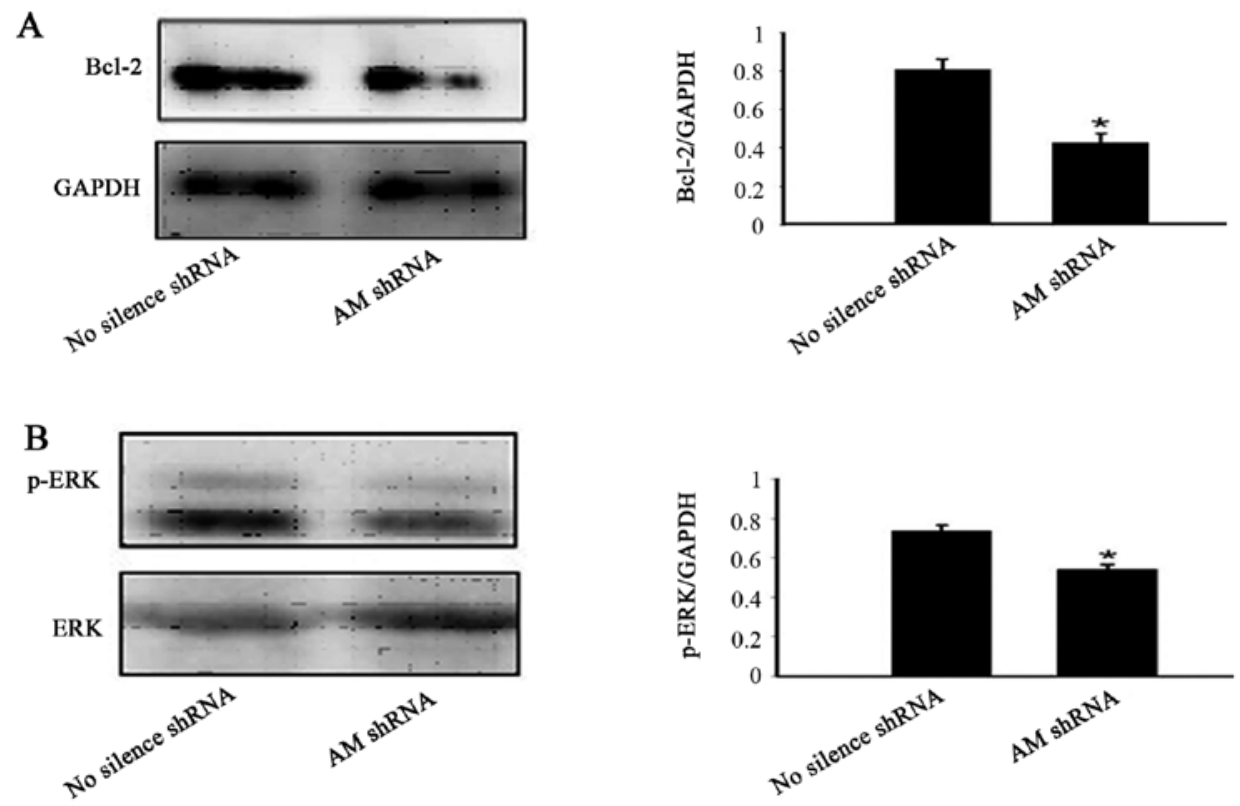

Figure 5. (A) Western blot analysis of the Bcl-2 protein levels in the AM shRNA group and the no silence shRNA group. Bcl-2 expression was significantly downregulated in the AM shRNA group relative to the no silence shRNA group. (B) Western blot analysis was also used to detect p-ERK protein levels in two groups. The p-ERK expression was significantly downregulated in the AM shRNA group compared to the no silence shRNA group. GAPDH was the internal loading control. The results are representative of three independent experiments performed in triplicate. Data are the mean \pm SEM. "P<0.05 vs. the no silence shRNA group.

AM is a multifunctional peptide that is widely expressed in many kinds of tumors (5). Treatment with antibody against AM caused a dose-dependent suppression of the growth in human tumor cell lines, including the human breast adenocarcinoma MCF-7 cells, the ovarian adenocarcinoma OVCAR-3 cells and the glioblastoma T98G cells (6). Therefore, endogenously produced AM by tumor cells is proposed to act as a growth stimulator for the tumors. Thus, treatment targeting the highly expressed AM gene has important significance in ovarian cancer. RNAi technology is a highly sequence-specific post-transcriptional gene silencing mechanism, induced by endogenous or extragenous double-stranded RNA (dsRNA) (7).

We searched the AM coding sequences in GenBank and selected three sequences in vitro to construct recombinant plasmids shRNA (AM shRNA1, AM shRNA2 and AM shRNA3) with pRNAU-6.1/neo as the expression vector. Then, the plasmids were stably transfected into human ovarian cancer HO8910 cells, which have effectively overcome the problems, such as short duration, difficulty in delivery in vivo and unstable transfection (8). We also selected an unrelated sequence as a negative control, which was also stably transfected to HO8910 cells, thus, rulling out other possible false-positive factors and we confirmed the significance of silencing the AM gene by RNAi. In the present study, RT-PCR, real-time PCR and western blot analysis were used to investigate AM mRNA and protein expression after transfection in HO8910 cells. Our results revealed that the AM expression level was successfully reduced with RNAi and gene transfection technology.

Ouafik et al (9) demonstrated that AM at $2 \times 10^{7} \mathrm{~mol} / \mathrm{l}$ stimulated the proliferation of the human glioblastoma cell line U87 by 13 and $12 \%$ after 6 and 8 days in vitro by the MTT assay. They also observed that anti-AM antibody could inhibit 
the growth of the cells in vitro and suppress tumor xenograft growth in vivo. The present study showed that after transfection, cell growth in AM shRNA group gradually slowed down with the increase of action time and the cell proliferation rate was inhibited. After transfection for $72 \mathrm{~h}$, the inhibiting effect was more obvious compared with the no silence shRNA group or the HO8910 group, suggesting that cell proliferation was blocked and/or apoptosis was stimulated. Thus, silencing AM with RNAi can significant inhibit the proliferation of HO8910 cells. In addition, after different concentrations of carboplatin treatment $(0-75 \mathrm{mg} / \mathrm{l})$, the most pronounced effects on the survival rate were noted in the AM shRNA group, suggesting that silencing of AM with RNAi can increase the chemosensitivity of HO8910 cells. Therefore, AM affects ovarian cancer cell proliferation and is related to drug susceptibility.

It has been reported that cell apoptosis is closely related to chemosensitivity and stimulating cell apoptosis may increase chemosensitivity of tumor cells (10). While, the apoptosis threshold of cells induced by chemotherapy is regulated by cell apoptosis and their metastatic potential for survival, abnormal activation or suppression of action events will affect the treatment results. The Bcl-2 gene is one of the final common pathways in the control of cell apoptosis. In recent years, research has suggested that $\mathrm{Bcl}-2$ is a new drug resistance gene (11). High expression of Bcl-2 can produce significant drug resistance in tumor cells, while suppressing its expression could promote apoptosis, which in return increases the chemosensitivity of tumor cells (12). In our previous study, we found that the AM receptor antagonist AM22-52 can block the activity of the ERK pathway in ovarian cancer cells, suggesting that AM may contribute to ovarian cancer through the MAPK/ ERK pathway. ERK is a member of the MAPK family, which controls proliferation and differentiation, shape maintenance and apoptosis, malignant transformation of cells and other biological response(13). Previous studies have demonstrated that activation of ERK achieved anti-apoptosis, and ultimately promoted tumor cell growth by phosphorylation anti-apoptotic molecule Bcl-2, activating transcription factors, and interferencing TRAIL(14). Consistent with these observations, our results showed that inhibiting the ERK signaling pathway and suppressing the apoptosis-related protein Bcl-2 expression with RNAi technology could inhibit cell proliferation, promote cell apoptosis, and thereby increase chemosensitivity of ovarian cancer cells.

In summary, in the present study, we first observed that silencing of AM in ovarian cancer HO8910 cells with RNAi technology inhibited the proliferation and increased the chemosensitivity of the cells through downregulating ERK and Bcl-2 expression. Thus, anti-AM treatment together with suppressing ERK and Bcl-2 expression provides a novel research approach for ovarian cancer.

\section{Acknowledgements}

This study was supported by the Liaoning Natural Science Foundation (no. 2009225035), the Liaoning Education Foundation (no. 2009A775), and the Shenyang Science and Technology Foundation (no. F11-262-9-14) to Y.Z.

\section{References}

1. Hata K, Takebayashi Y,Akiba S, Fujiwaki R, Iida K, Nakayama K, Nakayama S, Fukumoto M and Miyazaki K: Expression of the adrenomedullin gene in epithelial ovarian cancer. Mol Hum Reprod 6: 867-872, 2000.

2. Ramachandran V, Arumugam T, Hwang RF, Greenson JK, Simeone DM and Logsdon CD: Adrenomedullin is expressed in pancreatic cancer and stimulates cell proliferation and invasion in an autocrine manner via the adrenomedullin receptor, ADMR. Cancer Res 67: 2666-2675, 2007.

3. Zhang Y, Zhang SL, Shang H, Pang XY and Zhao Y: Basic fibroblast growth factor upregulates adrenomedullin expression in ovarian epithelial carcinoma cells via JNK-AP-1 pathway. Regul Pept 157: 44-50, 2009.

4. Zhang Y, Meng XK, Chen P and Liu L: Effects of AM and AM22-52 on activity of PKB in human ovarian epithelial cancer cells line CAOV3. Progress Anatom Sci 15: 298-300, 2009.

5. Takahashi K: Adrenomedullin from a pheochromocytoma to the eye: implications of the adrenomedullin research for endocrinology in the 21st century. Tohoku J Exp Med 193: 79-114, 2001.

6. Miller MJ, Martínez A, Unsworth EJ, Thiele CJ, Moody TW, Elsasser T and Cuttitta F: Adrenomedullin expression in human tumor cell lines. Its potential role as an autocrine growth factor. J Biol Chem 271: 23345-23351, 1996.

7. Trinchieri G and Sher A: Cooperation of Toll-like receptor signals in innate immune defence. Nat Rev Immunol 7: 179-190, 2007.

8. Yan G, Huang AL, Tang N, Zhang BQ, Pu D, Xiang MQ, Lan YH and Wu G: Inhibition of survivin expression in liver cancer cells by shRNA. Zhonghua Gan Zang Bing Za Zhi 11: 712-715, 2003.

9. Ouafik L, Sauze S, Boudouresque F, Chinot O, Delfino C, Fina F, Vuaroqueaux V, Dussert C, Palmari J, Dufour H, et al: Neutralization of adrenomedullin inhibits the growth of human glioblastoma cell lines in vitro and suppresses tumor xenograft growth in vivo. Am J Pathol 160: 1279-1292, 2002.

10. Wendt J, Radetzki S, von Haefen C, Hemmati PG, Güner D, Schulze-Osthoff K, Dörken B and Daniel PT: Induction of p21CIP/WAF-1 and G2 arrest by ionizing irradiation impedes caspase-3-mediated apoptosis in human carcinoma cells. Oncogene 25: 972-980, 2006.

11. Sullivan GF, Amenta PS, Villanueva JD, Alvarez CJ, Yang JM and Hait WN: The expression of drug resistance gene products during the progression of human prostate cancer. Clin Cancer Res 4: 1393-1403, 1998.

12. Adams JM and Cory S: The Bcl-2 apoptotic switch in cancer development and therapy. Oncogene 26: 1324-1337, 2007.

13. Ramos JW: The regulation of extracellular signal-regulated kinase (ERK) in mammalian cells. Int J Biochem Cell Biol 40: 2707-2719, 2008

14. Kim YH, Lee DH, Jeong JH, Guo ZS and Lee YJ: Quercetin augments TRAIL-induced apoptotic death: involvement of the ERK signal transduction pathway. Biochem Pharmacol 75: 1946-1958, 2008. 